\title{
APLIKASI MOBILE ZAPPELINE SEBAGAI MEDIA TEKNOLOGI MODIFIKASI CUACA (TMC) DAN PENIPISAN POLUTAN UDARA (ASAP)
}

\author{
Purwadi, Faisal Sunarto, Alfan Muttaqin, Tri Handoko Seto
}

\begin{abstract}
Intisari
Telah dilakukan kajian aplikasi mobile zappeline sebagai media teknologi modifikasi cuaca (tmc) dan media penipisan polutan udara (asap) pada sebuah truk Mitsubishi Colt Diesel berukuran 5,960 × 1,970 meter. Dengan kendaraan tersebut, direkomendasikan dimensi zappeline berbentuk bangun ruang eliptical dengan jari-jari diagonal $a$ dan $b$ masing-masing 3,25 dan 0,65 meter. Selanjutnya, karakteristik aerodinamik dan fisika dihitung dengan memecahkan beberapa persamaan fisika secara numerik pada kondisi atmosfer standart yaitu internasional standart of atmosphere (ISA). Pada kondisi standart ISA, maksimal beban pada ketinggian 1500 meter (5000 feet) sebesar 5,67 kg dan mampu mencapai ketinggian tersebut dalam waktu 1221.93 sekon (+/- 20 menit). Selanjutnya dilakukan perhitungan drag zappeline relatif terhadap udara yang disajikan dalam sebuah grafik yang dapat digunakan bahan pertimbangan dalam desain pendorong zappeline dan perhitungan kekuatan tali.
\end{abstract}

\begin{abstract}
Studies of mobile zeppeline aplication as a medium of weather modification technology and media thinning air pollutants (smoke) on a Mitsubishi Colt Diesel truck with dimensions of 5,960 × 1,970 meters have been done. With these vehicles, an elliptical zappeline shape geometry are recommended with diagonal radii $a$ and $b, 3.25$ and 0.65 meters, respectively. Then, the aerodynamics and physics characteristic are calculated by solving some physics equations numerically at standard atmospheric conditions of the international standard atmosphere (ISA). In the ISA standard conditions, the maximum load at 1500 meters altitude (5000 feet) is $5.67 \mathrm{~kg}$ and it is capable to reach that altitude in 1221.93 seconds (+/- 20 minutes). Furthermore, calculation of the air drag relative are presented in a graph that can be used in the design considerations of driving force zappeline and calculation of rope tension.
\end{abstract}

Kata kunci: Mobile Zappeline, teknologi modifikasi cuaca, penipisan polutan udara

\section{PENDAHULUAN}

Saat ini, Teknologi Modifikasi Cuaca (TMC) merupakan teknologi yang sedang menjadi sorotan di Indonesia dalam mengatasi berbagai bencana alam seperti banjir DKI Jakarta, penanggulangan kebakaran hutan dan lahan, dan juga bencana kekeringan. Selain untuk penanggulangan bencana, permintaan TMC juga bertujuan untuk pengisian waduk pada pembangkit listrik tenaga air (PLTA). Dari data UPT-Hujan Buatan BPPT, permintaan akan teknologi ini menunjukkan trend yang semakin meningkat. Namun, peningkatan permintaan tersebut tidak diiringi dengan peningkatan jumlah armada pesawat sebagai media pembawa bahan semai. Disisi lain, pemanfaat ground-based generator (GBG) dengan bahan semai flare hanya efektif pada jenis awan-awan orografik.

Teknologi lain yang sedang berkembang saat ini adalah teknologi penipisan polutan udara dan asap dengan menginisialisasi larutan kedalam atamosfer. Seperti diberitakan oleh situs internasional pada bulan Maret 2014, di China telah dikembangkan teknologi Unmaned Aerial Vehical (UAV) tipe paralayang untuk mendistribusikan larutan pengikat polutan kedalam atmosfer. Sedangkan di Indonesia, perkembangan teknologi ini masih menggunakan ground mist generator. Ground mist generator bersifat statis sehingga partikel yang tersebar tergantung dari faktor alam seperti angin dan aktivitas konveksi.

Beranjak dari topik teknologi di atas muncul ide pemanfaatan zappeline sebagai media pembawa material seeding maupun penipisan polutan dan asap. Ide yang disampaikan dalam karya tulis ini berupa gambar ilustrasi mobile zappeline, deskripsi tentang cara kerja, dan juga perhitungan karakteristik kerja dari teknologi ini.

\section{Dasar Teori \\ 2.1. Dasar Aerostatik}

Penggunaan gaya angkat gas sebagai sumber tenaga pada kapal/balon udara 
didasarkan pada prinsip Archimedes dan didefinisikan sebagai Principle Lift (PL). Gaya angkat ini disebabkan oleh perbedaan densitas antara gas dengan udara.

$$
P L=V\left(\rho_{A}-\rho_{G}\right)=V \Delta \rho, k g
$$

$V=$ Volume gas yang ada didalam $\mathrm{kapal} / \mathrm{balon}$ udara, $\mathrm{m}^{3}$

$\rho_{\mathrm{A}}, \rho_{\mathrm{G}}=$ densitas udara dan gas, $\mathrm{m}^{3}$

$\Delta \rho=$ Buoancy Spesifik untuk $1 \mathrm{~m}^{3}$ gas

Sedangkan, volume gas dan udara secara teori dapat ditentukan dengan persamaan Clapeyron untuk gas ideal.

$$
p v=R T ; v=\frac{R T}{p}=\frac{1}{\rho} ; \rho=\frac{p}{R T}
$$

Dimana;

$v=$ nilai gas spesifik, $\mathrm{m}^{3} / \mathrm{kg}$
$R=$ Konstanta gas, $\mathrm{kg} \cdot \mathrm{m} / \mathrm{kg}{ }^{\circ} \mathrm{C}$ (29.27 untuk udara, 424 untuk Hidrogen, dan 212 untuk helium)

$T=$ temperatur mutlak, ${ }^{\circ} \mathrm{K}$

$p=$ tekanan atmosfer, $\mathrm{kg} / \mathrm{m}^{2}$

Nilai perbedaan konstanta gas dipengaruhi oleh massa molekular $\mu$ dan konstanta gas universal $R$ $=848 \mathrm{Kgm} / \mathrm{kg}^{\circ} \mathrm{C}$, dengan rasio

$$
R_{i}=848 / \mu, \mathrm{kgm} / \mathrm{kg}^{\circ} \mathrm{C}
$$

Sebagai kesimpulanya, buoyancy terbesar dapat dihasilkan oleh gas yang memiliki massa molekular terkecil (Hidrogen, $\mu=2.0$, Helium $\mu=4.0$ ).

Densitas udara $\rho A$ pada persamaan 1 , merupakan nilai yang berubah tergantung kondisi atmosfer, cuaca, dan ketinggian. Karena sulit untuk mempertimbangkan semua parameter

Tabel 1. Tabel Internasional Standart Atmosphere (ISA) hingga ke tinggian 5000 meter.

\begin{tabular}{|c|c|c|c|c|c|c|c|}
\hline $\mathrm{H}$ & $\mathrm{p}$ & $\mathrm{T}$ & $\Delta$ & $v \cdot 10^{6}$ & $\lambda_{\mathrm{A}} \cdot 10^{2}$ & \multicolumn{2}{|c|}{$\Delta \rho=\rho_{\mathrm{A}}-\rho_{\mathrm{G}}$} \\
\cline { 7 - 8 } $\mathrm{m}$ & $\mathrm{mm}$ & ${ }^{\circ} \mathrm{K}$ & & $\mathrm{m} / \mathrm{s}$ & $\mathrm{Wt} /(\mathrm{m} \cdot \mathrm{K})$. & hydrogen & helium \\
\hline 0 & 760,00 & 288,00 & 1,0000 & 14,57 & 2,55 & 1,141 & 1,056 \\
\hline 500 & 715,98 & 284,75 & 0,9528 & 15,15 & 2,52 & 1,087 & 1,007 \\
\hline 1000 & 674,06 & 281,50 & 0,9074 & 15,77 & 2,50 & 1,035 & 0,959 \\
\hline 1500 & 634,14 & 278,25 & 0,8636 & 16,42 & 2,48 & 0,985 & 0,912 \\
\hline 2000 & 596,15 & 275,00 & 0,8215 & 17,20 & 2,45 & 0,937 & 0,868 \\
\hline 2500 & 560,04 & 271,75 & 0,7810 & 17,82 & 2,43 & 0,891 & 0,825 \\
\hline 3000 & 525,71 & 268,50 & 0,7420 & 18,60 & 2,40 & 0,847 & 0,784 \\
\hline 3500 & 493,11 & 265,26 & 0,7045 & 19,45 & 2,38 & 0,804 & 0,744 \\
\hline 4000 & 452,16 & 262,00 & 0,6685 & 20,30 & 2,35 & 0,763 & 0,706 \\
\hline 4500 & 432,81 & 258,75 & 0,6339 & 21,20 & 2,33 & 0,723 & 0,670 \\
\hline 5000 & 404,99 & 255,50 & 0,6007 & 22,10 & 2,30 & 0,685 & 0,635 \\
\hline
\end{tabular}

yang disebut diatas, beberapa tetapan kondisional digunakan dalam perhitungan. Beberapa tetapan untuk atmosfer didefiniskan oleh Internasional Standard Atmosphere (ISA) dalam sebuah persamaan. Persamaan ISA sampai ketinggian $11000 \mathrm{~m}$ ditunjukkan oleh persamaan oleh persamaan 4 dan 5 .

$$
\begin{gathered}
\frac{p}{p_{o}}=\left(1-\frac{H}{44300}\right)^{5,256} \\
\frac{\rho_{H}}{\rho_{o}}=\Delta=\left(1-\frac{H}{44300}\right)^{4.256}
\end{gathered}
$$

th $=15-0.0065 \mathrm{H},{ }^{\circ} \mathrm{C} ; \mathrm{P}_{0}=\mathrm{B}_{0}=760 \mathrm{~mm}=10331.7 \mathrm{~kg} / \mathrm{m}^{2}$

$H=$ ketinggian, $\mathrm{m}$

th = temperatur pada ketinggian $\mathrm{H},{ }^{\circ} \mathrm{C}$
$B_{0}=$ Tekanan atmosfer di atas permukaan laut, $\mathrm{kg} / \mathrm{m}^{2}$

\subsection{Gaya pada Zappelin}

Gambar 1 menjelaskan kompenen gaya yang bekerja pada zappeline yaitu kompenen vertikal dan horisontal. Komponen vertikal terdiri dari gaya angkat $\left(F_{\text {lift }}\right)$ yang mengarah keatas dan gaya berat $(W)$ dan gaya hambat $\left(F_{d v}\right)$. Sedangkan pada komponen horisontal terdiri dari gaya dorong $(F)$ dan gaya hambat $\left(F_{d h}\right)$ yang berlawanan arah dengan gerakan benda. 


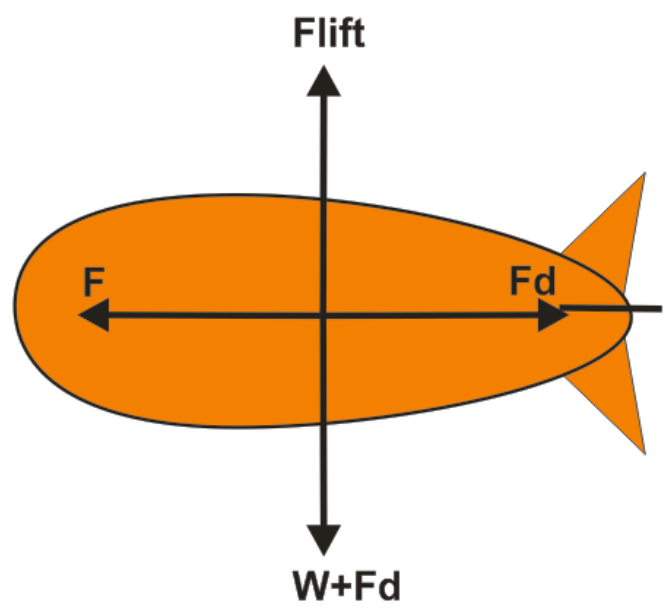

Gambar 1. Gaya pada Zappelin

\subsubsection{Komponen Gaya Vertikal}

Gaya angkat pada zappeline merupakan gaya angkat akibat gaya apungnya. Gaya apung pada sebuah benda di dalam fluida dapat dihitung menggunakan hukum Archimedes. Berdasarkan hukum Archimedes, besarnya gaya apung pada sebuah benda dalam fluida sebanding dengan berat fluida yang dipindahkan.

$$
F_{y}=\Delta \rho \cdot V \cdot g=P_{L} \cdot g
$$

Zappeline dapat naik keatas jika gaya apung lebih besar dari beban total zapeline $(W)$ ditambah dengan gaya friksi yang dialami oleh zappelin. Gaya friksi atau drag ( $F d)$ yang dialami oleh zappelin sebanding dengan kecepatan $(v)$ dan luas bidang frontal zappelin $(A)$. Bidang frontal pada arah gaya vertikal berupa bidang elips dengan jari-jari diagonal $a$ dan $b$ seperti terlihat pada gambar 3.a. Luas elips dirumuskan sebagai паab. Nilai $\mathrm{Cd}$ untuk beberapa geometri dapat dilihat pada gambar 2. Pada komponen gaya vertikal zappelin bentuk zappeline dapat dipandang sebagai sebuah lingkaran. Sehingga nilai $\mathrm{Cd}$ pada komponen gaya vertikal dapat diambil koefisien drag sebesar 0.47 .

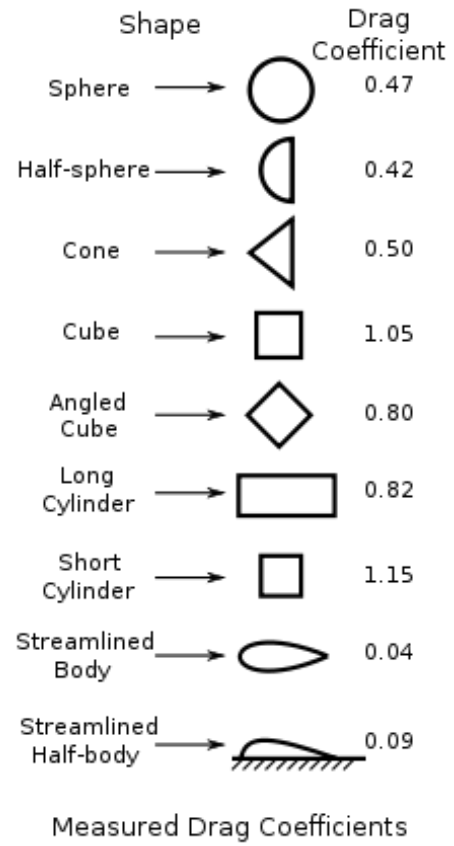

Gambar 2. Koefisien Drag

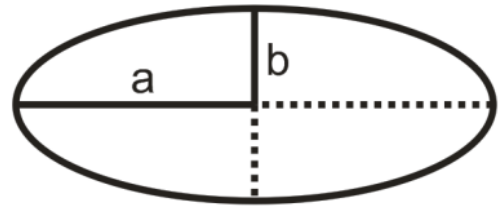

(a)

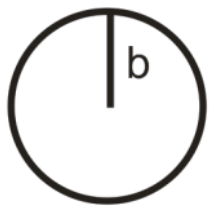

(b)
Gambar 3. (a) Penampang atas.

(b) penampang depan

$$
F_{d}=\frac{1}{2} \cdot \rho_{h} \cdot v^{2} \cdot C_{d} \cdot A
$$

Luas bidang frontal pada komponen drag vertikal berupa bidang elips dengan jari-jari diagonal a dan b, seperti terlihat pada gambar 3 . Luas elips dirumuskan sebagai mab.

Dari gambar 1 komponen gaya vertikal dapat dinyatakan dalam persamaan (8).

$$
\sum_{y} F_{y}=F_{y}-\left(W+F_{d y}\right)
$$

\subsubsection{Komponen Gaya Horisontal}

Komponen gaya horisontal terdiri dari gaya dorong (thrust) atau gaya tarik eksternal $F x$ yang diberikan dikurangi gaya hambat $F d x$. Komponen gaya pada bidang horisontal dinyatakan dalam persamaan 9 .

$$
\Sigma F x=F x-F d x
$$


Luas bidang frontal pada komponen drag horisontal berupa bidang lingkaran dengan jari-jari b seperti terlihat gambar 3.b. Luas lingkaran dirumuskan sebagai $m b^{2}$.

\section{METODE PENELITIAN}

Dalam tulisan ini disampaikan ide pembuatan mobile zappline pada sebuah kendaraan roda empat. Dimensi kendaraan yang digunakan, dijadikan acuan untuk menentukan dimensi zappeline. Kemudian, karakter zappeline pada dimensi tersebut dihitungan berdasarkan hukum aerostatik dan kinematika. Persamaan matematika yang diperoleh diselesaikan secara numerik menggunakan bahasa pemrograman $\mathrm{C}++$.

\section{HASIL PERANCANGAN}

\subsection{Mobile Zappeline}

Zappeline pada dasarnya adalah balon udara atau kapal udara. Pada umumnya, zappeline merupakan bangun berbentuk elips berisi gas yang lebih ringan dari udara luar sperti gas higrogen dan helium, sehingga zappeline akan terbang karena memiliki gaya apung yang lebih besar dari bebannya. Zappeline tidak memerlukan tenaga luar untuk dapat naik ke atas. Oleh karena itu zappeline memiliki efisiensi tenaga dalam hal gaya angkat.

Dari keuntungan tersebut muncul gagasan pemanfaatan zappeline untuk media penghantar bahan semai flare ataupun media pendispersi bahan penipisan polutan (asap). Untuk mencapai daerah sasaran zappeline harus dapat dikontrol dari bawah. Sedangkan pemanfaat radio kontrol untuk pengontrolan benda terbang sangat rumit dan beresiko menemui kegagalan. Oleh karena itu muncul ide penggunaan kendaraan darat untuk medekati sasaran pada arah horisontal, sedangkan arah vertikal memanfaatkan gaya apung yang dimiliki oleh zappeline. Ide mobile zappeline dituangkan dalam gambar 4.a.

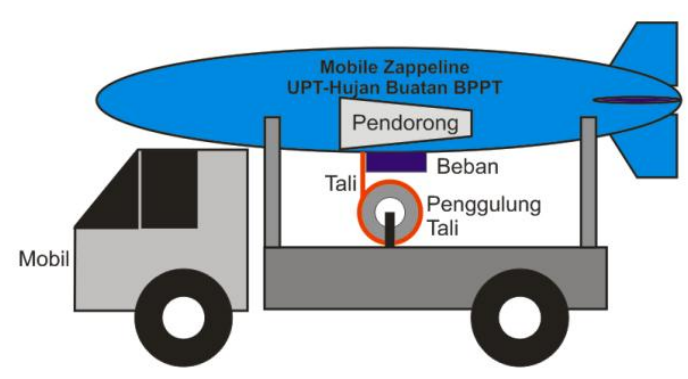

(a)

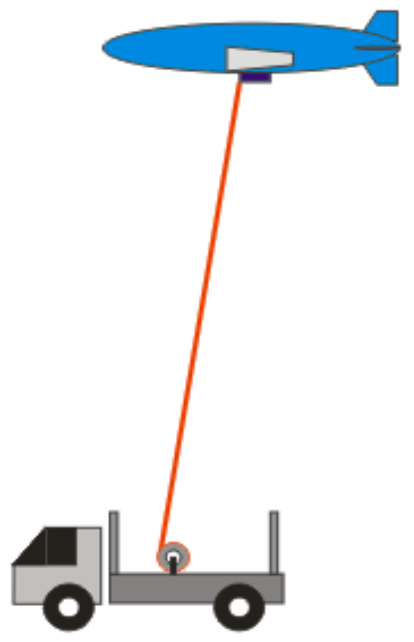

(b)

Gambar 4. Ilustrasi Mobile Zappeline (a) Zappaline parking (b) Zappeline sedang beroperasi.

Komponen utama mobile zappeline terdiri dari zappeline, mobil, tali, penggulung tali, beban, dan pendorong. Ilustrasi cara kerja mobile zappeline ditunjukkan pada gambar 4.b. Mobil atau truk akan membawa zappeline ke daerah target. Setelah sampai didaerah target zappiline di lepas dari landasanya dan penggulung mengulur tali. Beban diletakkan di posisi pusat grafitasi dari zappeline. Zappeline akan naik keatas karena gaya apungnya. Selain bergerak ke atas, zappeline bergerak mengikuti arah angin. Oleh karena itu, untuk memposisikan zappeline sesuai dengan target maka diperlukan tenaga pendorong. Pendorong pada zappeline dapat dikontrol menggunakan radio kontrol. Setelah misi selesai, zappeline dapat ditarik ke bawah dengan menggulung tali baik secara manual maupun menggunakan motor.

\subsection{Karakteristik Zappeline}

\subsubsection{Beban Maksimum}

Dalam desain mobile zappeline dimensi zappeline ditentukan oleh dimensi kendaraan. Dimensi zappelin ditentukan oleh dimensi kendaraan yang dipakai. Kedaraan yang di pakai merupakan jenis truk Mitshubishi Colt Diesel dengan dimensi 5,960 × 1,970 meter. Sedangkan dimensi zappeline berbentuk bangun ruang elips dengan jari-jari diagonal $a$ dan $b$ masing-masing 3.25 meter dan 0.65 meter. 
Gaya angkat pada zappeline didasarkan pada prinsip Archimedes. Gaya angkat pada benda dalam suatu fluida akan sama dengan berat fluida yang dipindahkan. Karena keadaan densitas udara dan suhu pada setiap ketinggian berubah maka besarnya gaya angkat zappeline juga akan berubah. Dalam perhitungan ini digunakan standar perubahan cuaca ISA dalam menentukan perubahan kondisi udara pada setiap level ketinggian. ISA standart menunjukkan densitas udara pada setiap kenaikan ketinggian menurun sehingga gaya angkat zappeline juga akan menurun. Hasil perhitungan untuk beban maksimum untuk setiap level ketinggian ditunjukkan oleh gambar 5. Gambar 5 menunjukkan terjadi penurunan beban maksimum secara linear pada setiap level ketinggian. Pada ketinggian 1500 meter ( \pm 5000 feet) beban maksimum zappeline yang didesain sebesar 5,67 $\mathrm{kg}$.

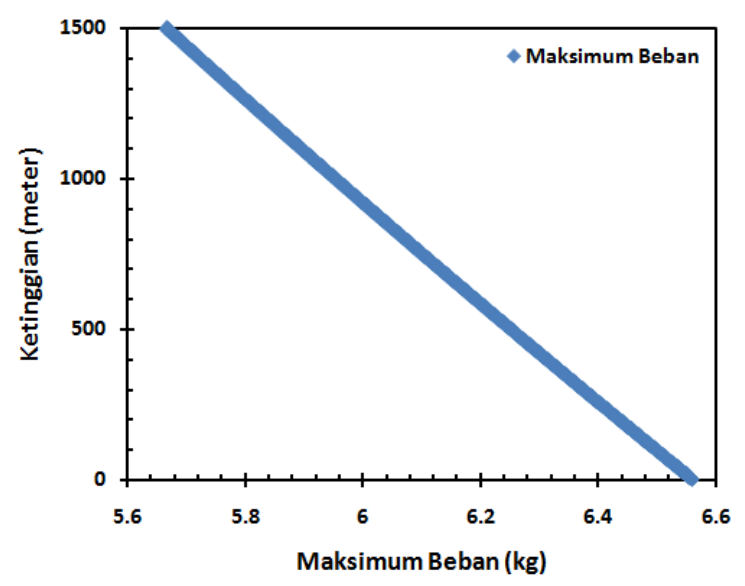

$\begin{array}{ll}\text { Gambar } & \text { Perubahan Beban } \\ \text { 5. } & \text { berdasarkan ketinggian. }\end{array}$

\subsubsection{Gerak dan Gaya pada arah Vertikal}

Dari persamaan 8 dinyatakan bahwa komponen gaya ke atas terdiri dari gaya angkat dikurangi dengan berat beban dan gaya gesek. Dengan mensubtitusi Nilai Fy dan Fdy masingmasing dengan persamaan 6 dan 7. Sedangkan $W$ merupakan total berat beban yang ditanggung oleh zapeline. Sehingga $W=M . g, M=$ total massa dan $g=9.8 \mathrm{~m} / \mathrm{s}^{2}$. Penyelesaian persamaan 8 dibagi dalam 2 kondisi, kondisi transisi dan kondisi steady. Pada kondisi transisi $\Sigma F_{y}=M . a$, yang menunjukkan resultan gaya lebih dari 0 . Sedangkankan pada kondisi steady $\Sigma F_{y}=0$ yang berarti terjadi kesetimbangan gaya. Dalam tulisan ini persamaan 8 diselesaian secara numerik dengan software $\mathrm{C}++$.
Kondisi transisi:

$$
M . a=\text { V.PL.g }-\left(M . g+0.5 \cdot \rho_{u} \cdot C d \cdot v^{2} \cdot A\right)(10)
$$

Variabel $M, V, g, C d$, dan $A$ merupakan variabel yang bernilai relatif konstan untuk ketinggian yang dituju. Dari persamaan isa standar nilai $P L$ dan $\rho_{u}$ tergantung dari ketinggian $h$.

$$
\Delta h=h_{n}-h_{n-1} \rightarrow h_{n}=\Delta h . n
$$

Sedangkan untuk nilai a pada ketinggian tertentu, dihitung dengan persamaan 12 .

$$
a_{n}=\frac{V \cdot P L \cdot g-\left(M \cdot g+0.5 \cdot \rho_{u} \cdot C d \cdot v_{n}^{2} \cdot A\right)}{M}
$$

Nilai $v=0$ saat $\mathrm{h}=0$.

Selanjutnya nilai $v$ pada ketinggian tertentu dapat dihitung dengan persamaan 13 .

$$
v_{n}=\sqrt{v_{n-1}^{2}+2 \cdot a_{n-1} \cdot \Delta h}
$$

Sedangkan untuk nilai $t$ dihitung dari rumus empirik,

$$
\Delta h=v_{n-1} \cdot \Delta t_{n}+\frac{1}{2} \cdot a_{n-1} \cdot \Delta t_{n}^{2}
$$

Persamaan di atas merupakan persamaan kuadrat terhadap variabel $\Delta t_{n}$. Nilai $\Delta t_{n}$ merupakan akar dari persamaan kuadrat tersebut. Dengan menggunakan rumus $\frac{-b \pm \sqrt{b^{2}-4 a c}}{2 a}$ untuk mencari akar persamaan kuadrat dan hanya mengambil nilai $\Delta t_{n}$ positif maka $\Delta t_{n}$ dapat ditentukan dengan;

$$
\Delta t_{n}=\frac{-v_{n-1}+\sqrt{v_{n-1}^{2}+2 \cdot a_{n-1} \cdot \Delta h}}{a_{n-1}}
$$

Selanjutnya, $t_{n}=t_{n-1}+\Delta t_{n}$

Kondisi steady:

Dalam kondisi ini $a=0$ untuk semua nilai $h$.

$$
0=V \cdot P L \cdot g-\left(M \cdot g+0.5 \cdot \rho_{u} \cdot C d \cdot v^{2} \cdot A\right)
$$

maka,

$$
v_{n}=\sqrt{\frac{V \cdot P L \cdot g-M \cdot g}{0.5 \cdot C d \cdot \rho_{u} \cdot A}}
$$

Sedangkan untuk nilai $t_{n}$ dicari dengan;

$$
\Delta t_{n}=\frac{\Delta h}{v_{n-1}}
$$


Penyelesaian secara numerik untuk kedua kondisi diatas digunakan $\Delta h$ yang mendekati 0 , semakin kecil nilai $\Delta h$ maka hasil yang didapatkan akan semakin akurat. Dengan nilai $\Delta h=1.10^{-3}$ meter didapatkan penyelesaian berupa grafik $t$ versus $h$ yang ditunjukkan gambar 6.a. Kondisi transisi dan steady ditunjukkan oleh gambar 6 b. Saat kondisi transisi kecepatan mengalami peningkatan secara signifikan, sedangkan saat steady zappeline mengalami penurunan kecepatan secara perlahan.

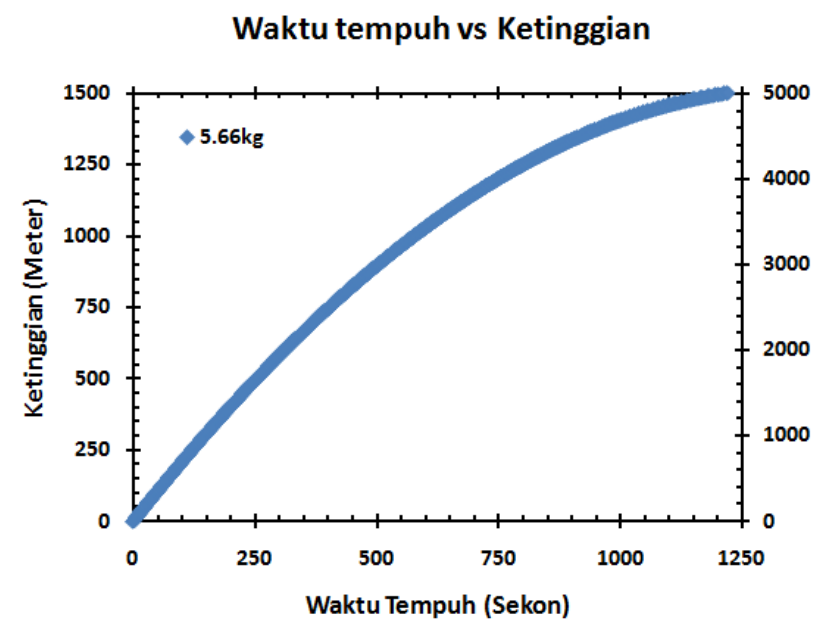

(a)

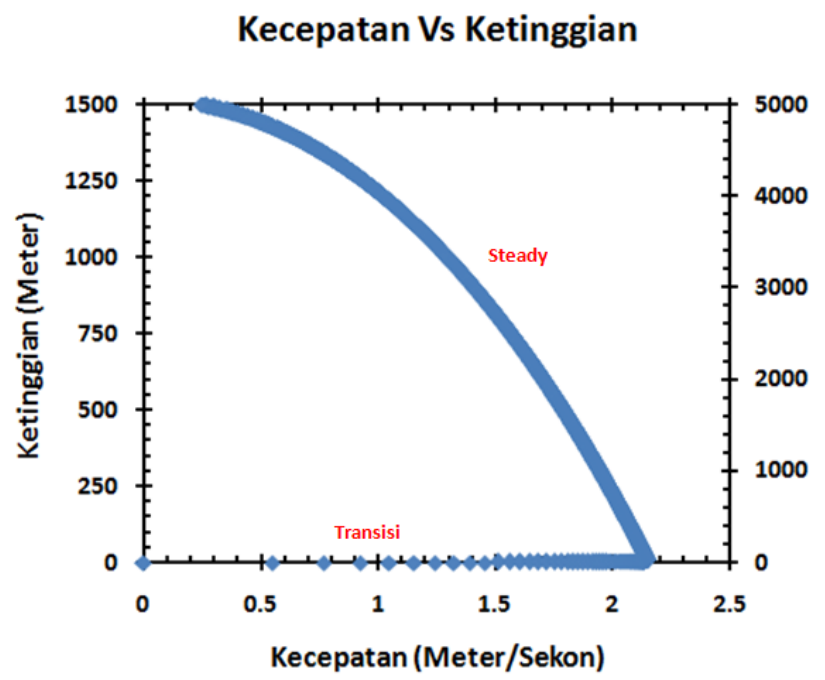

(b)

Gambar 6. performa gerak vertikal zappeline. (a) Grafik waktu tehadap ketinggian yang dicapai. (b) Grafik kecepatan terhadap ketinggian.

\subsubsection{Gaya pada arah Horisontal}

Gaya pada arah horisontal merupakan gaya gesek (drag) zappeline dengan udara yang bergerak relatif terhadap zappeline. Drag relatif zappeline terhadap udara pada arah horisontal dapat digunakan untuk menentukan besarnya gaya pendorong, batasan zappeline terhadap kondisi angin, dan juga tegangan tali. Hasil perhitungan untuk komponen gaya horisontal ditunjukkan oleh gambar 7 .

\section{Horizontal Drag Vs Kecepatan}

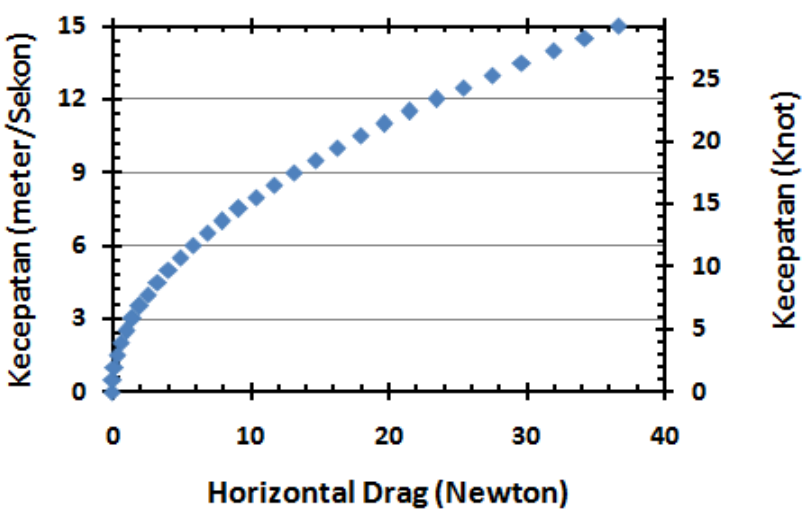

Gambar 7. Grafik Horizontal Drag relatif terhadap Kecepatan Udara

\section{DISKUSI/ PEMBAHASAN}

Gambar 3 menunjukkan hasil perhitungan beban maksimum yang dapat dicapai zappeline pada setiap ketinggian. Semakin tinggi target, beban maksimum yang diijinkan semakin kecil. Sehingga, beban maksimum untuk desain zappeline di tentukan dari target ketinggian yang akan dicapai. Dalam desain mobile zappeline untuk TMC target ketinggian merupakan dasar awan. Awan-awan potensial yang menjadi target TMC adalah awan-awan cumulus yang memiliki dasar awan yang rendah yang memiliki dasar awan kurang dari 5000 feet. Sehingga dalam tulisan ini diambil ketinggian target maksimum $5000 \mathrm{ft}$ dan didapatkan beban maksimum $5,67 \mathrm{~kg}$. Beban maksimum merupakan beban total sehingga purwarupa yang dibuat harus seringan mungkin sehingga menyisakan ruang untuk muatan yang lebih besar. Berat sebuah bahan semai flare +/- $1 \mathrm{~kg}$, sehingga jika diharapkan mobile zappeline membawa 2 buah flare akan menyisakan ruang desain purwarupa sebesar $3,67 \mathrm{~kg}$.

Berbeda dengan aplikasi mobile zappeline pada TMC, aplikasi mobile zappeline untuk penipisan asap memiliki target ketinggian lebih rendah. Selain itu dengan sifatnya yang mobile, teknologi ini akan lebih fleksibel daripada ground mist partikel generator dalam hal penempatan yang harus mengikuti arah adatangnya angin. Keuntungun lain dari teknologi ini tidak diperlukan landasan yang luas dan panjang, karena mobile zappeline take off dan landing dalam arah vertikal. 
Jika diambil ruang desain purwarupa 3,67 seperti pada aplikasi untuk TMC maka untuk aplikasi penipisan polutan asap, teknologi ini dapat membawa 2 liter larutan dengan asumsi 1 liter air sama memiliki berat $1 \mathrm{~kg}$.

Dilihat dari waktu tempuh vertikal pada gambar 6.b, berturut-turut zappeline akan mencapai ketinggian 1000, 2000, 3000, 4000, dan $5000 \mathrm{ft}$ dalam waktu 2.5, 5.3, 8.5, 13, dan 20 menit. Dilihat dari waktu tempuh yang relatif singkat, teknologi ini masih memberikan keuntungan untuk diterapkan baik untuk TMC maupun media pendispersi larutan penipisan polutan udara (Asap).

Gambar 7 menunjukkan grafik kecepatan udara relatif terhadap gaya drag horisontal. Dari grafik tersebut disimpulan bahwa drag akan semakin besar untuk kondisi angin semakin besar. Sehingga diperlukan tenaga pendorong yang besar untuk kondisi angin yang semakin besar. Kemampuan pendorong zappeline untuk menghendel kondisi angin dijadikan batasan untuk area kerja zappeline. Sehingga prediksi kecepatan angin diperlukan sebelum teknologi ini digunakan. Selain itu, tegangan tali juga dapat dihitung dengan menghitung resultan gaya vertikal dan horisontal, yang mana gaya horisontal dipengaruhi oleh kondisi angin.

\section{KESIMPULAN}

Aplikasi mobile zappeline sebagai media tmc dan penipisan polutan udara (asap) diilustrasikan dalam bentuk sketsa gambar, merupakan kombinasi antara kendaraan darat dengan balon udara zappeline. Pada sebuah truk Mitsubishi Colt Diesel berukuran 5,960 x 1,970 meter, direkomendasikan dimensi zappeline berbentuk bangun ruang eliptikal dengan jari-jari diagonal a dan b masing-masing 3,25 dan 0,65 meter. Dengan dimensi tersebut, maksimal beban pada target ketinggian 1500 meter (5000 feet) dan kondisi atmosfer sesuai dengan ISA, sebesar 5,67 $\mathrm{kg}$ dan mampu mencapai ketinggian tersebut dalam waktu 1221.93 sekon (+/- 20 menit). Hasil perhitungan tersebut menunjukkan bahwa teknologi ini memungkinkan untuk diterapkan untuk aplikasi tersebut dan memberikan keuntungan tersendiri dibanding teknologi lain untuk tujuan yang sama.

\section{DAFTAR PUSTAKA}

Lutz, Cyril et.al, 1998, The Airship "Simon", Realgymnasium Rämibühl 8001 Zürich.

Konstantinov, L: The Basics of Gas and Heat Airship Theory. Unpublished
Cavcar, Mustafa, The International Standart Atmosphere (ISA), Anadolu University, 26470 Eskisehir, Turkey

\section{SITUS}

http://therundownlive.com/chinese-drone-sprayschemicals-to-capture-pollution/

http://www.dailymail.co.uk/news/article-

2574052/China-use-drones-clear-smog-filled-

skies-spraying-pollution-chemicals-make-particlesfall-ground.html

http://www.dailymail.co.uk/sciencetech/article2577347/China-successfully-tests-smog-fightingdrones-spray-chemicals-capture-air-pollution.html 
